\title{
Regenerative Aerobraking
}

\author{
Robert W. Moses \\ Exploration Systems Engineering Branch, NASA Langley Research Center, Hampton, VA 23681 \\ (757) 864-7033; Robert.W.Moses@NASA.GOV
}

\begin{abstract}
NASA's exploration goals for Mars and Beyond will require new power systems and in situ resource utilization technologies. Regenerative aerobraking may offer a revolutionary approach for in situ power generation and oxygen harvesting during these exploration missions. In theory, power and oxygen can be collected during aerobraking and stored for later use in orbit or on the planet. This technology would capture energy and oxygen from the plasma field that occurs naturally during hypersonic entry using well understood principles of magnetohydrodynamics and oxygen filtration. This innovative approach generates resources upon arrival at the operational site, and thus greatly differs from the traditional approach of taking everything you need with you from Earth. Fundamental analysis, computational fluid dynamics, and some testing of experimental hardware have established the basic feasibility of generating power during a Mars entry. Oxygen filtration at conditions consistent with spacecraft entry parameters at Mars has been studied to a lesser extent. Other uses of the MHD power are presented. This paper illustrates how some features of regenerative aerobraking may be applied to support human and robotic missions at Mars.
\end{abstract}

\section{INTRODUCTION}

The tremendous amount of kinetic energy needed for interplanetary transit is wasted during planetary entry. As an example, a rover-class spacecraft having a mass of 2000 kilograms and an initial velocity of 7000 meters per second, looses nearly 50 gigajoules of kinetic energy by the time it reaches the planet's surface. Understanding the potential to capture some of the interplanetary kinetic energy and use it for a Mars mission has motivated this technology called regenerative aerobraking. An interplanetary hyperbolic trajectory from Earth must be converted to a direct entry or an elliptic orbit for the spacecraft to be captured by the planet. If aerobraking is used, converting this hyperbolic trajectory involves turning kinetic energy into atmospheric heat. The heated atmosphere ionizes into plasma to release electrons in large densities and ions that dissociate into several molecular species. The properties of this plasma about the spacecraft resemble those of gases used in magnetohydrodynamic (MHD) power generation. To be sure, laboratory experiments in simulated Martian gas and analysis including computational fluid dynamics support this claim (Moses, 2002; Moses, 2003; Moses, 2004; Gnoffo, 2001; Vuskovic et. al., 2003; and Macheret et. al., 2004). Furthermore, although the atmosphere of Mars is $95 \%$ carbon dioxide, large quantities of oxygen are present in some regions of the plasma (Gnoffo, 2001; and Vuskovic et. al., 2003).

However, the bigger challenge may be making use of the MHD power once it is generated. As will be presented herein, current energy storage technologies must be massive to store the large amount of MHD power as it is generated. In one case to be presented later herein, the 50 gigajoules of kinetic energy are converted to heat within sixty seconds. Thus, other alternatives for using or storing the energy have been investigated. In concept, regenerative aerobraking could benefit the Mars mission by 1) reducing the thermal protection system mass or increasing the drag, lift, or controlling the location and shape of the shock layer; 2) providing power to some coolant system that maintains safe temperatures for key spacecraft components at or near the stagnation region, for instance; 3 ) increasing the strength of a transmission signal so to mitigate black-out periods caused by the ionization sheath that encapsulates the spacecraft during entry; 4) collecting electrical energy and storing it in some form for later use on the surface or in orbit; 5) harvesting oxygen from the atmosphere that occurs naturally during the ionization phase of the Martian entry; or 6) scooping up and compressing a large amount of $\mathrm{CO}_{2}$ for processing into oxygen and fuel later. This paper will present some preliminary analysis for these uses of the MHD power.

\section{Aerobraking Maneuvers}

Two types of deceleration maneuvers have been demonstrated at Mars. First, the direct entry (DE) has been used for placing landers and rovers on the surface of Mars, such as the Mars Pathfinder (Spencer et. al., 1999) and both Mars Exploration Rovers (Raofi et. al., 2002). This maneuver converts the energy of the hyperbolic trajectory from Earth to heat in one pass through the Martian atmosphere to reach a safe landing on the planet surface. Parachutes and 
chemical propulsion augment drag and control the placement and deceleration of the payload. As shown in Figure 1, the velocity drops by two-thirds of its initial value within forty seconds. In that same period, the kinetic energy drops by nearly ninety percent.

The second maneuver used by spacecraft that orbit Mars, for example Odyssey (Smith et. al., 2002) and Mars Reconnaissance Orbiter (Lyons et. al., 2002), converts the kinetic energy of the hyperbolic trajectory from Earth to drag through hundreds of passes through the Martian atmosphere, after an initial orbit burn. Because the spacecraft looses kinetic energy over a longer period in this case, a multi-pass maneuver may be more suitable to current energy storage technologies for collecting the MHD power as it is generated. However, one consequence of this orbit is that very little heat is generated on any pass. Without heat, the atmosphere does not ionize, and an MHD generator will be ineffective.

A study was conducted to examine the trade between ionization levels, in the form of electron number density, and the number of passes. As indicated in Figure 2, the electron number density at Mars is affected by entry velocity and atmospheric density. The electron number density governs the power output of a MHD generator (Rosa, 1987). The conductivity of the gas, the current density of the gas, and the power output are linearly proportional to electron number density. These properties of the flow can be enhanced significantly by a process known as seeding whereby the electron number density is greatly increased by the addition of small amounts of potassium or cesium (Rosa, 1987). Thus, as long as the velocity of the spacecraft maintains values shown in Figure 2, then MHD power generation is feasible. This paper will include some results of this multi-pass orbit trade study.

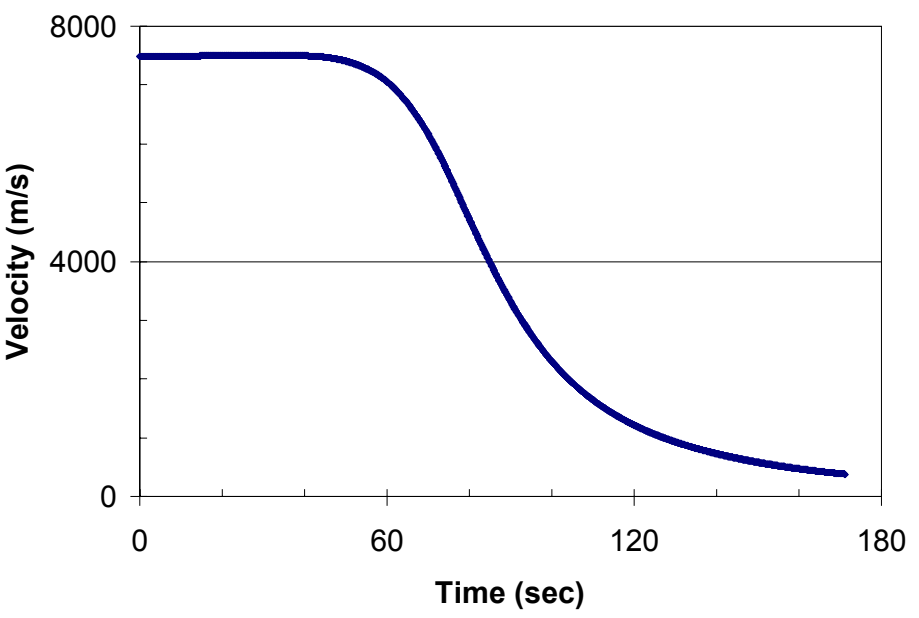

FIGURE 1. Velocity Profile for a Direct Entry Case at Mars.

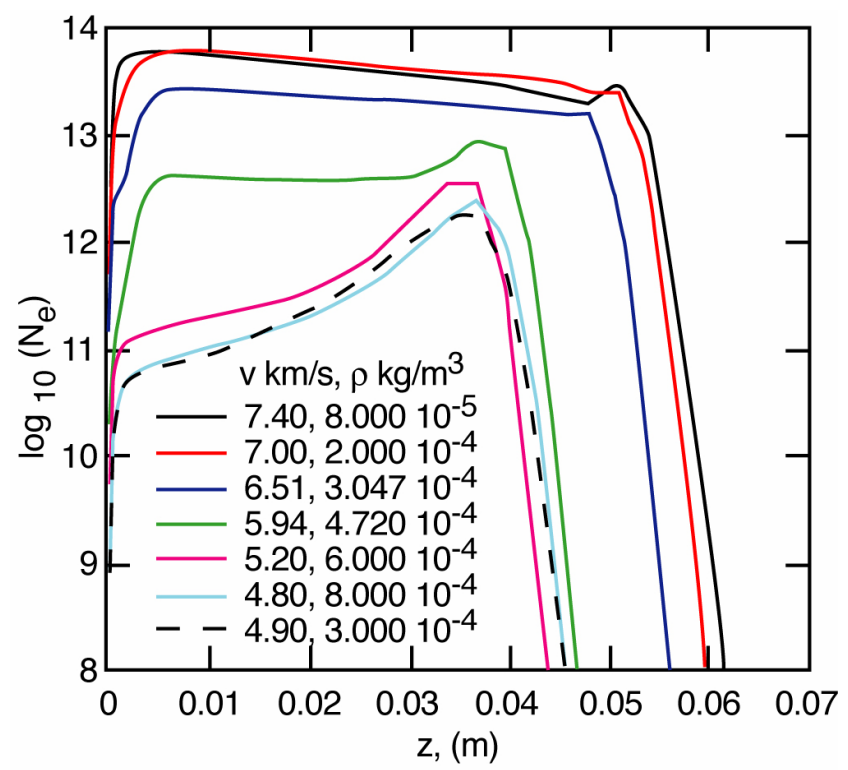

FIGURE 2. Electron Number Density for a Family of Velocities and Densities possible during Mars entry. The ZAxis is Distance in Meters Ahead of the Outer Mold Line of the Spacecraft Moving to the Right

\section{MAGNETOHYDRODYNAMIC (MHD) ENERGY CONVERSION}

Magnetohydrodynamic generator transforms the energy of the plasma into electric power. The MHD generator is particularly well suited for those applications involving high power, high temperature, or both (Rosa, 1987). As illustrated in Figure 3, aerobraking provides both. The material within the MHD generator ionizes under these conditions. When the electrons and ions encounter a magnetic field, they are forced to the electrode corresponding to their polarity. The path of least resistance for the electron is to travel onto the anode, along the wire, through the load to recombine with the ion on the cathode, as illustrated in Figure 4. 


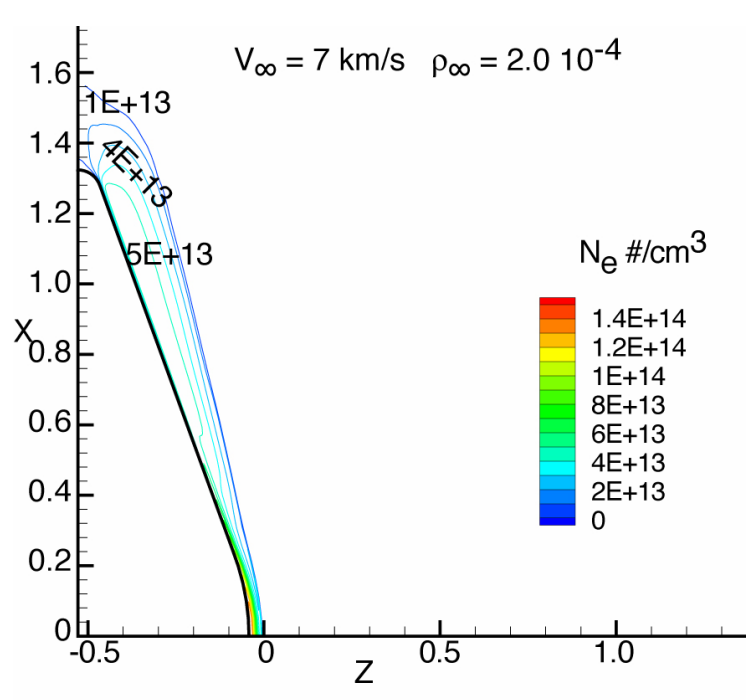

(a) Electron Density Number

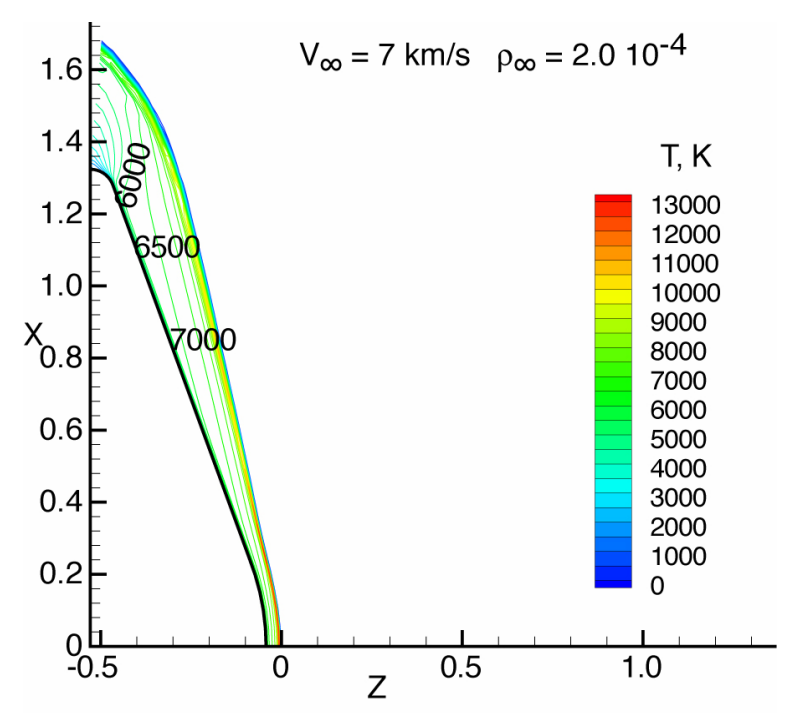

(b) Temperature

FIGURE 3. Some Atmospheric Properties Within the Flow Field Near the Front of the Spacecraft During one Direct Entry Trajectory at Mars. The Units of Atmospheric Density $(\rho)$ are Kilograms per Cubic Meter. The Spacecraft is Moving to the Right (Z-Axis). Distance from the Centerline of the Spacecraft is Along the X-Axis. The Outer Mold Line of the Spacecraft, from Centerline Nose to Distal Shoulder, is Represented by the Heavy Dark Line. The Color Contours Illustrate the Properties Between the Shock Layer and the Spacecraft.

In the context of regenerative aerobraking, two types of MHD power generators have been studied. First, the traditional internal MHD generator, shown in Figure 4, consists of a duct down which the gas flows, an arrangement of coils that produce a magnetic field across the duct, and electrodes on either side that carry off the current. Represented by Equation 1 , the power output is a function electron number density $\left(\mathrm{N}_{\mathrm{e}}\right)$, the square of the velocity (u) and the magnetic field strength (B), the cross-sectional area of the duct $\left(\mathrm{A}_{\mathrm{c}}\right)$, and the interaction length $\left(\mathrm{L}_{\mathrm{i}}\right)$. In general, internal MHD generators have an efficiency of about $25 \%$. The advantage of the internal MHD generator is that most of the ionized plasma passes through the duct and interacts with the magnetic field and the electrodes. One challenge for implementing the internal concept within a spacecraft is that temperature-sensitive components need to be shielded from the hot gas in the channel.

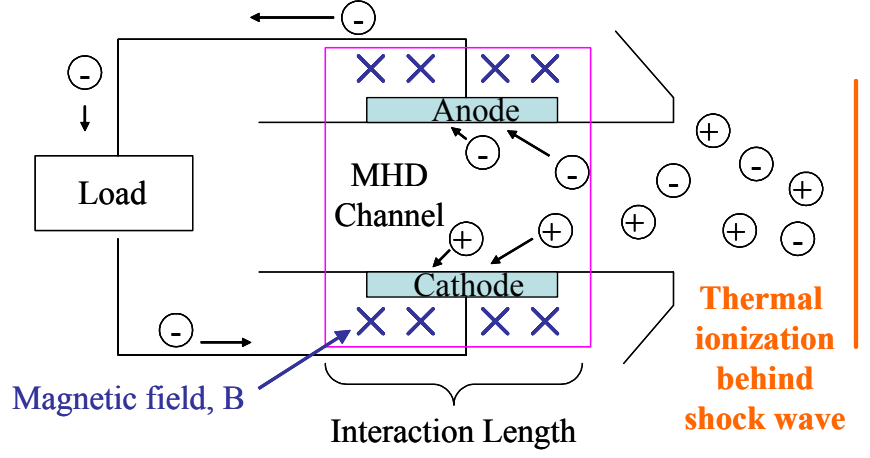

FIGURE 4. Schematic Diagram of an Internal Magnetohydrodynamic Power Generator

$$
\operatorname{Pg} \sim\left(\mathrm{N}_{\mathrm{e}}\right) \mathrm{u}^{2} \mathrm{~B}^{2} \mathrm{~A}_{\mathrm{c}} \mathrm{L}_{\mathrm{i}}
$$

The second type of MHD power generator, which was conceived during this project, does not contain a duct. Coined an external MHD power generator, this new type takes advantage of the boundaries formed by the outer mold line of the spacecraft and the shock layer just ahead of the spacecraft, as shown in Figure 3. In concept, magnets just behind the outer wall of the spacecraft project the magnetic field into the flow field to force the ions to hit the electrodes protruding out of the surface toward the shock layer. The advantage of the external concept is that no hot gases enter the spacecraft. The challenge of this concept centers around the material selection for the electrodes, any seeding nozzles, and the thermal protection system on the front of the spacecraft. One concept under study, called active ablator, adds seeding material to the ablator material near the MHD generator to seed the flow. 


\section{MHD Power Generation during Direct Entry}

For the direct entry trajectory, the power that can be generated for the direct entry velocity profile, shown in Figure 5, equates to about 14 megajoules, based on a minimal size MHD generator having an area of $1 \mathrm{~m}^{2}$ (Macheret et. al., 2004). As indicated in Figure 5, the power is generated over a period of approximately 30 seconds. No seeding is required. The challenges facing the implementation of regenerative aerobraking into the direct entry is that the energy storage devices must be capable of collecting quickly the large amount of energy at high power. Because of this challenging constraint, the direct entry does not offer an attractive case for implementing regenerative aerobraking using current technologies for energy storage or usage, as will be demonstrated later herein. Thus, a more attractive

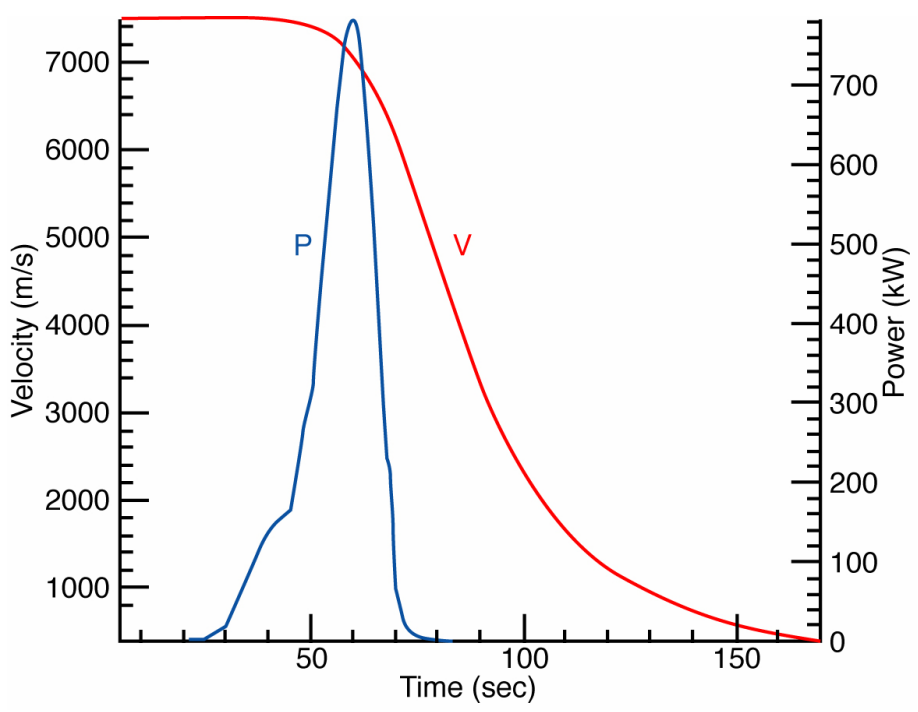

FIGURE 5. Power Extraction Profile for a Direct Entry at Mars approach may be to harvest power at lower levels for longer periods of time. To do this requires a different type of orbit.

\section{MHD Power Generation during Multi-Pass Maneuvers}

As mentioned earlier, multi-pass orbits about Mars allow longer time periods to extract power. The intent of regenerative aerobraking is to provide resources to benefit operations on Mars after maximizing the time spent in the atmosphere generating power and extracting other resources, like oxygen. This entails multiple passes through the atmosphere, at velocities to produce sufficient electron number densities, followed by the descent and landing. The terminology of $E^{i} D L$ is used to define this orbit approach, where " $\mathrm{i}$ " denotes the number of passes (entries) before the eventual descent (D) and landing (L). The number of passes can be varied by changing the ballistic coefficient. To generate these different cases, the ballistic coefficient was varied by changing the presumed surface area of the vehicle (Tolbert, 2004). For the first case, the area is presumed at $7 \mathrm{~m}^{2}$, and is dropped by one-half for each subsequent case. The resulting orbits for three cases of $E^{i} \mathrm{DL}$ are $\mathrm{i}=3,7$, and 11 as shown in Figure 6 . The average entry properties based on preliminary calculations using Satellite Tool Kit and MarsGRAM (Justus, 1990) are as follows: 1) velocity around $4.5 \mathrm{~km} / \mathrm{sec} ; 2$ ) average atmospheric density is $8 \times 10-5 \mathrm{~kg} / \mathrm{m}^{3}$; and 3) average time in the atmosphere is 550 seconds per orbit.

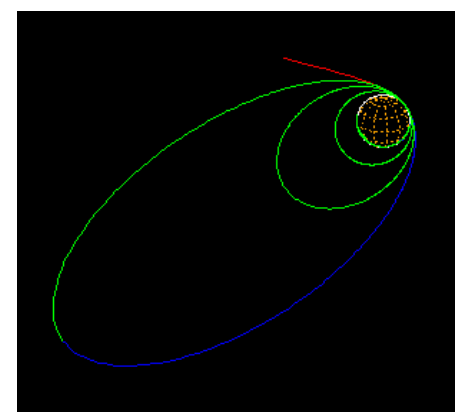

(a) Full Area $\left(7.0 \mathrm{~m}^{2}\right)$

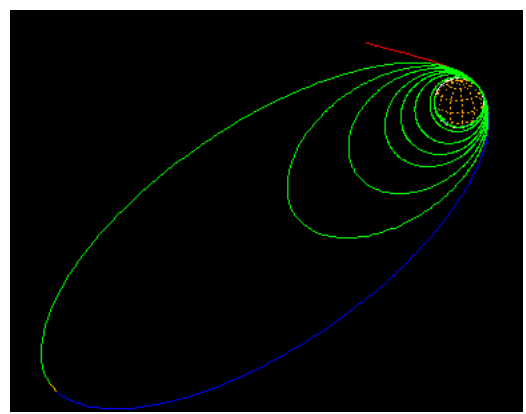

(b) Half Area (3.5 $\left.\mathrm{m}^{2}\right)$

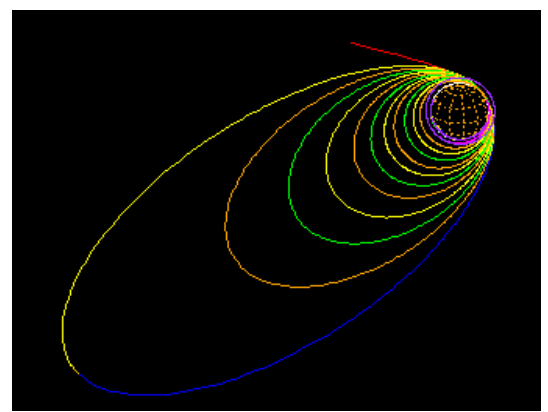

(c) Quarter area $\left(1.75 \mathrm{~m}^{2}\right)$

FIGURE 6. Illustration of $E^{i} D L$ Orbits for $i=3,7$, and 11

Shown in Table 1, for the multi-pass cases for $\mathrm{i}=3,7$, and 11, respectively, the total times spent in the atmosphere are 1881 seconds, 4390 seconds, and 7400 seconds, respectively. Although the velocities for these cases are just 
below $5 \mathrm{~km} / \mathrm{sec}$, resulting in lower electron number densities (Figure 2) than the direct entry case (Figure 3), the MHD power can be boosted by seeding the flow (Macheret et. al., 2004). Based on these estimates, the energy that can be generated per orbit is approximately 500 megajoules per $1 \mathrm{~m}^{2}$ of external MHD generator area. For each case, the number of passes can be increased by compensating for the atmospheric drag occurring during each pass. One way to compensate for the drag is to perform a delta- $\mathrm{V}$ on the order of tens of meters per second at apoapsis following each pass through the atmosphere. This option will be addressed later as an energy usage.

TABLE 1. Properties of $E^{i} D L$ Orbits, Cases for $i=3,7$, and 11

\begin{tabular}{|c|c|c|c|c|}
\hline Configuration & No. of Passes & Avg. Density $\left(\mathrm{kg} / \mathrm{m}^{3}\right)$ & Avg. Velocity $(\mathrm{km} / \mathrm{s})$ & Total Time in Atmosphere (s) \\
\hline Full Area & 3 & 0.00008 & 4.5 & 1881 \\
\hline $1 / 2$ Area & 7 & 0.00008 & 4.5 & 4390 \\
\hline $1 / 4$ Area & 11 & 0.00008 & 4.5 & 7400 \\
\hline
\end{tabular}

\section{ENERGY USAGES}

The challenge for regenerative aerobraking involves using the power once it has been harvested from the plasma field. Energy can be stored, used immediately, or transmitted off-board. The prospects for storage and immediate use are examined for technical feasibility and cost/mass tradeoffs, as follows: 1) reducing the thermal protection system mass or increasing the drag by controlling the location and shape of the shock layer; 2) providing power to some coolant system that maintains safe temperatures for key spacecraft components at or near the stagnation region, for instance; 3 ) increasing the strength of a transmission signal so to mitigate black-out periods caused by the ionization sheath that encapsulates the spacecraft during entry; 4) collecting electrical energy and storing it in some form for later use on the surface or in orbit; 5) harvesting oxygen from the atmosphere that occurs naturally during the ionization phase of the Martian entry; or 6) scooping up and compressing a large amount of $\mathrm{CO}_{2}$ for processing into oxygen and fuel later.

\section{Reducing Thermal Protection System (TPS) Mass or Increasing Drag, Lift, or Control Moments}

One study evaluated the potential of MHD interactions with the flow about high speed re-entry vehicles (Jarvinen, 1964). The MHD effects on trajectory, forces, and resultant heating rates were calculated. These re-entry applications were found attractive if superconducting magnets are used to mitigate joule dissipation in the coils and are capable of a current density of 100,000 amps per square centimeter. This current density lies well within the realm of current and emerging magnet technologies (LyTec, 2002).

\section{Actively Cooling Temperature-Sensitive Components}

Current thermal protection systems (TPS) are sized by regulating the temperature at the bond line between the heatshield and the backing structure providing structural stability to the aeroshell and payload. The bond line near the stagnation region of the heatshield is most at risk, and moreso during a direct entry. To provide active cooling to this region may be feasible. For instance, some gases do not require cryogenics to keep as liquid, for reducing system complexity and mass. The working fluid can be pushed through a capillary system that runs near the stagnation region and then to cold parts of the spacecraft that can absorb the heat. Thus, the thermal load that is normally concentrated near the stagnation region would be spread over a larger region to reduce the thermal stresses on the bond line near the stagnation region. The power consumption of a coolant system is limited by the MHD power generated during the direct entry. This coolant system may be a suitable trade, in terms of mass and complexity, in the case where a spacecraft is rotated so that the stagnation region is moved to other parts of the heatshield to reduce burn-through of the TPS.

\section{Mitigating Black Out Periods or Transmitting Power}

There is considerable opportunity in this use of the MHD power. First, the ionization sheath encapsulating the spacecraft can be reduced greatly by implementing MHD power generation. The strength of the ionization sheath 
that encapsulates the spacecraft is greatly reduced in specific areas as electrons and ions are redirected by the magnetic field and harvested at the electrodes. Directing the signal through these areas of reduced ionization, especially toward the back of the vehicle, may enable communications during the entire entry. One approach to mitigate black out periods has been investigated already (Belov et. al., 1999). That approach extended a shaft through the ionization sheath to place a transmitter outside the cloak of the ionization sheath. Second, if feasible, this approach may stimulate future work in the transmission of power off the spacecraft to a receiver, where it can be stored or used elsewhere. Currently, no assets exist on Mars or its moons to allow this option. Therefore, one possibility may be to beam the power to another spacecraft that is leaving Mars, returning to Earth, or heading to another planet or moon. The electron number densities must be considerably higher than those reported herein to achieve meaningful power levels for this application.

\section{Energy Storage}

The ability of an energy storage device to accept power at a high rate is proportional to its mass. Therefore the metric for energy storage normalizes the amount of time a specific power can be applied by the weight of the device. Energy storage devices were surveyed and compared; see Figure 7 (Ribeiro et. al., 2001, and LyTec, 2002). The best technology is toward the upper right of the graph. Current technologies are about equal in this metric, with capacitors comprising the largest range of specific power with respect to specific energy. However, other more promising technologies are on the horizon. Carbon nanotube (CNT) technology promises to increase the capacity and reduce weight of current energy storage devices. An estimate of the impact of carbon nanotubes (CNT) on superconductivity magnetic energy storage (SMES) is annotated in the graph. Without CNT, the SMES system will weigh as much as 100 kilograms for the direct entry case and approximately 3000 kilograms for the multi-pass orbit case, provided the energy can be transmitted off the vehicle after each pass. With CNT, the SMES system would weigh considerably less, perhaps on the order of 200 kilograms, based on current projections of the CNT technology (LyTec, 2002). Until then, batteries may provide a better alternative for the multi-pass case since the energy is generated at lower power levels. Batteries would weigh around 2000 kilograms for that

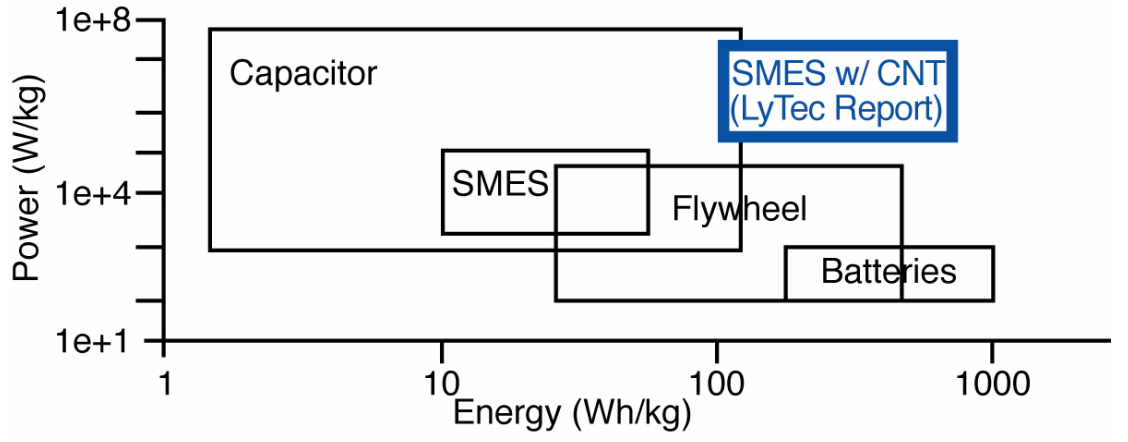

FIGURE 7. Specific Power Versus Specific Energy Ranges for Near-to-Midterm Technology (Figure 1 from Ribeiro et. al., 2001 with Additions Stemming from Author's Understanding of LyTec Report, 2002) case.

\section{Harvesting Oxygen From the Plasma}

The elevated temperatures of aerobraking at Mars temporarily free oxygen from the carbon dioxide in the plasma stream. As illustrated in Figure 8, for direct entry at Mars, the amount of oxygen in the stagnation region is considerably greater than any of the other molecular species found there. In the region ahead of the spacecraft, oxygen makes up roughly 50 percent of the mole fraction, followed by carbon monoxide comprising around 30 percent. Recognizing this feature initiated a survey of oxygen filtration technologies, which led to a process called solid oxide electrolysis.

Many studies propose the use of solid oxide electrolysis for extracting oxygen from the carbon dioxide rich atmosphere at Mars (Sridhar et. al., 1995; Crow, 1997; and Minh et. al., 1998). These concepts use a low-power device that heats the carbon dioxide, provides a voltage potential across a zirconia membrane using platinum electrodes, and draws oxygen across the membrane into a separate reservoir for storage. This process, illustrated in Figures 9 and 10, and represented by the reaction (2), requires approximately 283 kilojoules to convert 1 mole of $\mathrm{CO}_{2}$, or 9 kilojoules to produce 1 gram of $\mathrm{O}_{2}$. For the direct entry case, the MHD (per unit area of $1 \mathrm{~m}^{2}$ ) will 
generate $14 \mathrm{MJ}$ of energy to process roughly 1.5 kilograms of oxygen. For the multi-pass case, that same MHD generator will provide $500 \mathrm{MJ}$ of energy to process roughly 55 kilograms of oxygen.

$$
\mathrm{CO}_{2}+\text { Power } \Rightarrow \mathrm{CO}+\frac{1}{2} \mathrm{O}_{2}
$$

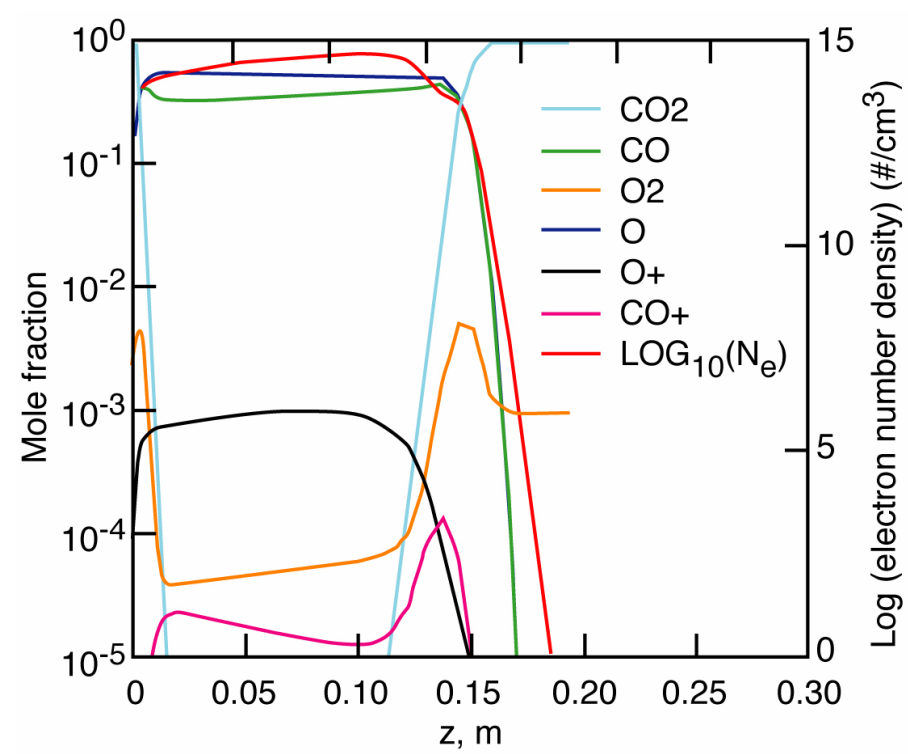

FIGURE 8. Molecular Species by Mole Fraction and Electron Number Density in Stagnation Region During Martian Entry, Entry Velocity 7 $\mathrm{km} / \mathrm{sec}$ and Density $2 \times 10^{-4} \mathrm{~kg} / \mathrm{m}^{3}$

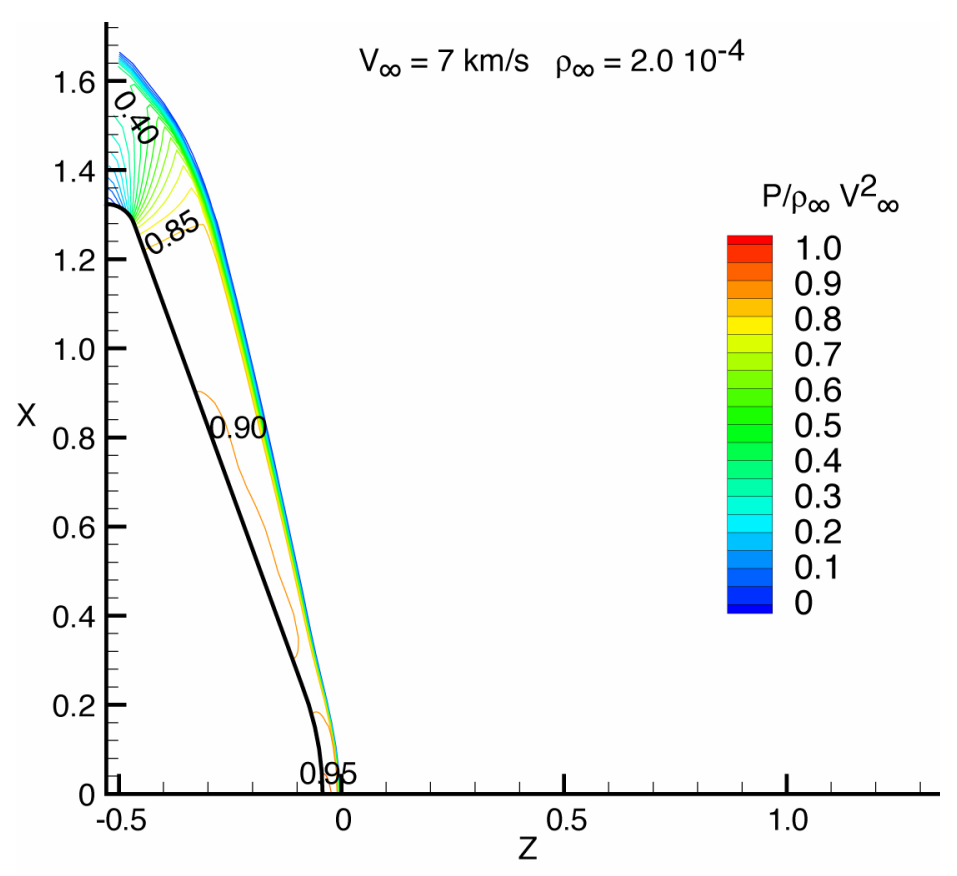

FIGURE 11. Pressure Near the Nose of the Spacecraft During a Direct Entry at Mars. The Units of Atmospheric Density are Kilogram per Cubic Meter. The Outer Mold Line of the Spacecraft's Front from Centerline to Shoulder is Shown by the Heavy Line on the Inner Wall (left side) of the Shock Wave Indicated by the Color Contour Lines.

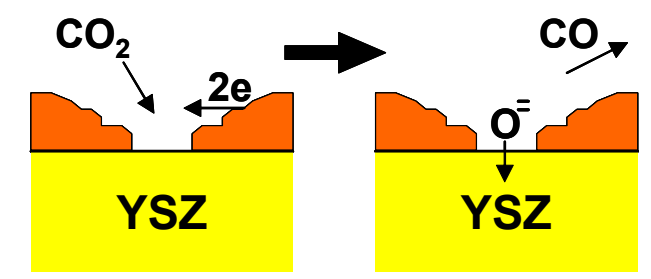

FIGURE 10. Three Phase Boundary Within a Solid Oxide Electrolysis Cell (Sridhar et. al., 1995)

The process works best when the carbon dioxide is hot and the pressure on the carbon dioxide side of the membrane is higher than on the oxygen side of the membrane. These conditions are provided during atmospheric entry at Mars (Figures 3.b. and 11).

Molar flow rates of oxygen through the zirconia can be found in the literature, but for low power conditions. Three features from these studies apply to this application: 1) molar flow rates appear linear with electrical current up to the maximum current density of the ion conductor; 2) ion conductors are more efficient when oxygen is present in the gas mixture; and 3) ion conductor acts as a fuel cell (gives energy) 
when the pressure on the upstream surface is higher than the pressure on the downstream (oxygen) surface (Taylor, 2004). Shown in Figure 11, the pressures in the stagnation region (near the nose) of the spacecraft are highest providing an opportunity to extract oxygen and energy with the ionic conductor, thus reducing the reliance on MHD power generation. One concept for integrating the MHD power generation and solid oxide electrolysis technologies into a spacecraft is illustrated in Figure 12. The inlets are placed near the stagnation region (nose) of the spacecraft to take advantage of the increased pressures there. For the multipass orbit case, the temperatures in the stagnation region will be far less than the temperatures occurring during direct entry. The heat rate varies as a function of velocity cubed (Smith and Bell, 2002). Thus, the heat rate for the multi-pass cases (Table 1) will be about 25 percent of the heat rate for a direct entry (Figure 1).

\section{Harvesting Carbon Dioxide from the Atmosphere for Later Processing}

Carbon dioxide would be scooped during the multiple passes through the atmosphere. During each pass at the density, velocity, and duration specified earlier, approximately 200 kilograms of carbon dioxide can be scooped up using a scoop area of $1 \mathrm{~m}^{2}$. Seeding would be used to boost MHD power generation to levels sufficient to compress the carbon dioxide into tanks. As a point of reference, storing this carbon dioxide in liquid form would require approximately 1.5 megajoules per kilogram. Liquid form is preferred to minimize volume within the spacecraft. Using a scoop rate of approximately 0.3 kilograms per second (200 kilograms per orbit in about 550 seconds per orbit), the power required for this process is around 0.5 megawatts. Analysis results stated above suggest that there is sufficient MHD power and energy during the multi-pass orbit to merit this approach. The advantages of this approach seem numerous: 1) the temperatures of the atmosphere would be lower than the direct entry, reducing the need for thermal protection in the scoop region; 2) the solid oxide electrolysis unit could be removed from the spacecraft allowing more room for other components; 3) the stored carbon dioxide would be under pressure, enabling a solid oxide electrolysis system to act as a fuel cell while processing the carbon dioxide to oxygen; 4) keeps the oxygen locked in a stable, possibly liquid, form without cryogenics; 5) there is no dependence on the amount of dissociation of the plasma to produce oxygen in large quantity; and 6) the dependence on molar flow rate is relaxed because the oxygen processing would not have to be completed while the spacecraft is in the atmosphere. The pressurized carbon dioxide could be used as propellant to provide the delta-v to compensate for atmospheric drag, to raise periapsis, or to break orbit at Mars for reaching another planet or moon.

\section{SUMMARY OF SYSTEM ESTIMATES}

The system estimates for energy harvesting using MHD, energy storage, oxygen filtration, and carbon dioxide scooping are summarized for the two entry cases, in Table 2. Three important results (Table 2) highlight the ISRU features of Regenerative Aerobraking. First, the multi-pass orbit provides a better case $\left(1.5 \mathrm{~kg}\right.$ vs. $\left.55 \mathrm{~kg} \mathrm{per} \mathrm{m}{ }^{2}\right)$ for extracting resources from the Martian atmosphere. Second, scooping up $\mathrm{CO}_{2}$ and storing it for later processing provides for an even more productive (55 kg vs. $145 \mathrm{~kg}$ per $\mathrm{m}^{2}$ per orbit) ISRU opportunity. In the latter, the MHD power would be used to compress the $\mathrm{CO}_{2}$ into storage tanks and processed into oxygen later perhaps using another power source. Third, storing the MHD energy requires considerably more mass for the multi-pass case than for the direct entry case. 
Based on surface requirements at Mars, an astronaut needs approximately $1 \mathrm{~kg}$ per day (Zubrin et. al., 1993). Current estimates indicate that the direct entry case could provide nearly 2 days of oxygen (per $\mathrm{m}^{2} \mathrm{MHD}$ area). Since the nominal spacecraft for reaching the surface of Mars can provide approximately $10 \mathrm{~m}^{2}$ of surface area for MHD power generation, this option provides roughly 20 days of oxygen. On the other hand, current estimates indicate that the multi-pass orbit case offers an appealing opportunity of oxygen production per astronaut, roughly 550 days of oxygen per orbit for the same spacecraft size (based on an efficiency of $100 \%$ ). Furthermore, this oxygen is produced relatively quick compared to other ISRU oxygen production technologies.

TABLE 2. Summary of Estimates for MHD Power Generation and Selected Energy Uses

\begin{tabular}{|c|c|c|}
\hline & Direct Entry & Multi-Pass Orbit \\
\hline $\begin{array}{l}\text { Harvested Energy (Per } \mathrm{m}^{2} \text { MHD per orbit) } \\
\text { No seed / seeded (Macheret et.al., 2004) }\end{array}$ & $14 \mathrm{MJ} / \mathrm{nc}$ & $0 / 500 \mathrm{MJ}$ \\
\hline $\begin{array}{l}\text { Energy Storage mass (Per } \mathrm{m}^{2} \text { MHD per orbit) } \\
\text { SMES without/with CNT technology }\end{array}$ & $100 \mathrm{~kg} / 10 \mathrm{~kg}$ & $3000 \mathrm{~kg} / 200 \mathrm{~kg}$ \\
\hline $\begin{array}{c}\text { Available } \mathrm{O}_{2} / \mathrm{CO}_{2}\left(\text { Per m }{ }^{2} \text { scoop area per orbit) for }\right. \\
\text { the atmospheric densities shown }\end{array}$ & $\begin{array}{l}30 \mathrm{~kg} / 42 \mathrm{~kg} \\
2 \times 10^{-4} \mathrm{~kg} / \mathrm{m}^{3}\end{array}$ & $\begin{array}{l}145 \mathrm{~kg} / 200 \mathrm{~kg} \\
8 \times 10^{-5} \mathrm{~kg} / \mathrm{m}^{3}\end{array}$ \\
\hline Harvested $\mathrm{O}_{2}\left(\right.$ Per $\mathrm{m}^{2} \mathrm{MHD}$ area per orbit $)$ & $1.5 \mathrm{~kg}$ (if initially $\mathrm{CO}_{2}$ ) & $55 \mathrm{~kg}$ (if initially $\mathrm{CO}_{2}$ ) \\
\hline MHD Mass (Per $\mathrm{m}^{2}$ MHD area per orbit) & $\begin{array}{l}100 \mathrm{~kg} \\
\text { (Steeves et. al., 2004) }\end{array}$ & $\begin{array}{c}100 \mathrm{~kg} \\
\text { (Steeves et. al., 2004) }\end{array}$ \\
\hline
\end{tabular}

\section{CONCLUSIONS}

Based on estimates stemming from fundamental analysis, Regenerative Aerobraking offers tremendous potential as an ISRU concept in providing oxygen to astronauts for months while they explore Mars. MHD power generation and oxygen filtration through solid oxide electrolysis seem feasible based on related work in the field. However, further research is needed to understand the implications of joining these two technologies on an interplanetary spacecraft. Another option of storing the MHD energy seems feasible; however, this approach can be greatly enhanced by the emergence of carbon nanotube (CNT) technology.

\section{ACKNOWLEDGMENTS}

The author wishes to express his deepest gratitude to Dennis Bushnell for inspiring a study to examine the use of MHD power generation during Martian entry. The findings reported herein could not have been possible without the contributions of Peter Gnoffo, Mark Saunders, Charles McClish, Robert Dillman, Warren Kelliher, David Alexander, John Cole, Sergey Macheret, Reginald Exton, Svetozar Popovic, John Buckley, Dale Taylor, Douglas Tolbert, Joseph Parker, Nirvana Mehan, Erin Gatling, Melanie Fox, Daniel Chattin, Chris Kuhl, Juan Cruz, Will Scott, and Justin Templeton, for which the author is sincerely grateful.

\section{REFERENCES}

Belov, I.F., Borovoy, V.Ya., Gorelov, V.A., Kireev, A. Yu., Korolev, A.S., and Stepanov, E.A., "An Experience in the Investigation of a Radio Communications System for a Reentry Vehicle on the Plasma Flight Trajectory Portion," AIAA-99-3739, 30 ${ }^{\text {th }}$ Plasmadynamics and Lasers Conference, 28 June -1 July, 1999, Norfolk, Virginia.

Crow, S., "The MOXCE Project - New Cells for Producing Oxygen on Mars," AIAA-1997-2766, AIAA/ASME/SAE/ASEE Joint Propulsion Conference and Exhibit, 33 ${ }^{\text {rd }}$, Seattle, WA, July 6-9, 1997. 
Gnoffo, P.A., "Computational Aerothermodynamics in Aeroassist Applications," AIAA-2001-2632, 15" AIAA Computational Fluid Dynamics Conference, 11-14 June 2001, Anaheim, California.

Jarvinen, P.O., "On the Use of Magnetohydrodynamics During High Speed Re-Entry," Avco-Everett Research Laboratory, Research Note 463, July 1964.

Justus, C., "A Mars Global Reference Atmospheric Model (MarsGRAM) for Mission Planning and Analysis," AIAA-90-0004, $28^{\text {th }}$ Aerospace Sciences Meeting, January 8-11, 1990, Reno, Nevada.

Lyons, D., "Mars Reconnaissance Orbiter: Aerobraking Reference Trajectory," AIAA-2002-4821, AIAA/AAS Astrodynamics Specialist Conference and Exhibit, 5-8 August 2002, Monterey, California.

LyTec, LLC, "Flight-Weight Magnets Using Carbon Nanotubes," LyTec-R-02-012, May 2, 2002.

Macheret S., Shneider, M., Candler, G., Moses, R., Kline, J., "Magnetohydrodynamic Power Generation for Planetary Entry Vehicles", AIAA-2004-2560 35th AIAA Plasmadynamics and Lasers Conference, Portland, Oregon, June 28-1, 2004

Minh, N., Chung, B., Doshi, R., Montgomery, K., Ong, E., Reddig, M., MacKnight, A., and Fuhs, S., "Zirconia Electrolysis Cells for Oxygen Generation from Carbon Dioxide for Mars In-Situ Resource Utilization Applications," SAE Paper 981655, 1998 SAE Transactions Journal of Aerospace.

Moses, R.W., "Regenerative Aerobraking," 2002, 2003, and 2004 Final Reports and Presentations, Creativity \& Innovation Program Review, NASA Langley Research Center, 2002, 2003, and 2004.

Raofi, B., Bhat, R., and D'Amario, L., "Flight Path Control Strategies for the 2003 Mars Exploration Rover (MER) Mission," AIAA-2002-4824, AIAA/AAS Astrodynamics Specialist Conference and Exhibit, 5-8 August 2002, Monterey, California.

Ribeiro, P.F., Johnson, B.K., Crow, M.L., Arsoy, A., and Liu, Y., "Energy Storage Systems for Advanced Power Applications," IEEE Vol. 89, No. 12, page 1745, December 2001.

Rosa, R. J., Magnetohydrodynamic Energy Conversion, Hemisphere Publishing Corporation, New York, 1987, pp. $1-9$.

Smith, J. and Bell, J., "2001 Mars Odyssey Aerobraking,” AIAA-2002-4532, AIAA/AAS Astrodynamics Specialist Conference and Exhibit, 5-8 August 2002, Monterey, California.

Spencer, D., Blanchard, R., Braun, R., Kallemeyn, P., and Thurman, S., "Mars Pathfinder Entry, Descent, and Landing Reconstruction," Journal of Spacecraft and Rockets, Vol. 36, No. 3, May-June 1999.

Sridhar, K.R., Vaniman, B.T., "Oxygen Production on Mars using Solid Oxide Electrolysis," SAE Paper 951737, $25^{\text {th }}$ International Conference on Environmental Systems, San Diego, California July 1995.

Steeves, C.A., Wadley, H.N.G., Miles, R.B., and Evans, A.G., "A Magnetohydrodynamic Power Panel for Space Re-Entry Vehicles," April 15, 2004, submitted to the AIAA Journal and provided through private communication.

Taylor, D., Ceramatec, Inc., personal communications with author, August - October 2004.

Tolbert, D.R., "Fourth Progress Report to NASA Langley Research Center," August 5, 2004.

Vuskovic, L., and Popovic, S., "Magnetohydrodynamic Power Generator," Summary of Research Report for ODURF Project \#133931, March 2004.

Zubrin, R.M., Weaver, D.B., "Practical Methods for Near-Term Piloted Mars Missions," AIAA/SAE/ASME/ASEE $29^{\text {th }}$ Joint Propulsion Conference and Exhibit, Monterey, California, June 28-30, 1993. 